\title{
Open Source ERP, What Opportunity for Moroccan SMEs? Case Study of a Moroccan Agribusiness SME
}

\author{
Achargui Amine Arrahmane and Zaouia Abdellah
}

INPT CEDOC EM2TI, Rabat, Kingdom of Morocco

Correspondence should be addressed to: Achargui Amine Arrahmane;

achargui.amine.arrahmane@gmail.com

Received date: 5 October 2015; Accepted date: 10 February 2016; Published date: 21 September 2016

Academic Editor: Rachid Oumlil

Copyright (C 2016. Achargui Amine Arrahmane and Zaouia Abdellah . Distributed under Creative Commons CC-BY 4.0

\begin{abstract}
Although there is no universal definition for Small and medium sized enterprises (SME), they represent the majority of the economic sphere worldwide. As large enterprises, profit maximization is SMEs major goal, so here emerges the need for effective information management and efficient decision making through integrating business processes, and this is the role of Enterprise Information Systems (EIS). Enterprise Resource Planning (ERP) systems are one facet of modern EIS, that were, until recently, targeted to Large Enterprises only, due to the expensive costs of an ERP project as well as to organizational issues for the case of SMEs.This ongoing research paper aims at doing a mix of both theoretical and practical research. On the one hand, we conduct a literature review of what has been advanced as academic and professional published works concerning the subjects of Free/Libre \& Open Source (FLOSS) ERP systems, Cloud ERP systems, ERP systems adoption: motives, benefits and barriers. On the other hand, a practical research is conducted through observation of a Moroccan agribusiness SME, adopting, implementing and using an Open Source ERP system.
\end{abstract}

Keywords: Free/Libre and Open Source Software, Enterprise Resource Planning, Small and medium sized Enterprise, Agribusiness, Moroccan SME

\section{Introduction}

In Morocco, SMEs are vital for the growth of the national economy, according to a report realized by the Moroccan Ministry of Finance and Privatization (August 2003), titled
"Evaluation of SME financing in Morocco", they represent over $95 \%$ of companies, occupy $50 \%$ of employees, and realize $31 \%$ of exports, $51 \%$ of national investment and $40 \%$ of production. Moroccan SMEs contribution to Gross Domestic Product

Cite this Article as: Achargui Amine Arrahmane and Zaouia Abdellah (2016), "Open Source ERP, What Opportunity for Moroccan SMEs? Case Study of a Moroccan Agribusiness SME ", Journal of African Research in Business \& Technology, Vol. 2016 (2016), Article ID 636830, DOI: 10.5171/2016.636830 
(GDP) is limited to about $20 \%$ against $60 \%$ in some countries. Those statistics put the emphasis on the potential that SMEs have in bringing substantial contribution to the Moroccan economy. In addition to being aware of the fact that SMEs can provide new industries with a strong growth foundation along with strengthening existing ones, the Moroccan legislator has established new mechanisms and arrangements for overcoming the mainly perceived knowledge gaps as to funding, organization and technology. It is, therefore, one of the many instruments of a policy whose purpose is the establishment of a favorable climate for the creation, development and prosperity of SMEs.

As Lord Kelvin said, "If you cannot measure it, you cannot improve it." An Enterprise information system converts data from internal and external sources into information, and communicates that information in an appropriate form to users at all levels and all parts of that Enterprise. This enables them to make timely and effective operational, tactical and strategic decisions for planning, directing and controlling the activities for which they are responsible.

The geographical, technological and functional separation of information per unit / department is a generally shared observation in our SMEs. Silos are created when different departments, sites do call for the use of different tools, technology and standards over time for operational and analytical data manipulation. These information "silos" created barriers to the intra-enterprise and extra-enterprise exchange of information, and posed significant challenges for both executives and managers within the same organization and building. Thanks to the central repository, a single point of acquisition, storage and distribution of data and information across all consumers-providers in one or more organizations, adopting and implementing an ERP system that is intended to facilitate information sharing, business planning, and decision making on an enterprise-wide basis, not only increases the reliability of past, present and future business data but also serves to break down information silos, thus minimizing duplicate data acquisitions, performed by various departments and units within the same organization. Moreover, its modular application design, offered by ERP systems, solves specific and immediate business challenges with the opportunity to expand and evolve to enterprise perspective over time instead of creating additional silos of information.

On the one hand, ERP Vendors till recently targeted Large Enterprises only, due to the expensive costs of an ERP project as well as to SMEs common organizational issues. Lately, they are re-discovering the SME market benefiting from trends in the IT industry that have contributed to making ERP systems available to smaller businesses. We cite as an example, the web revolution which reduces the enterprise IT investment on two fronts-hardware and personnel, and the raise of small PC-based networks which became much faster, more flexible, and cheaper than mainframes. On the other hand, Free/Libre and Open Source Software (FLOSS) actors, namely community and corporations, after the great success within the IT infrastructure, and development libraries, comes the turn to focus on developing and delivering business applications like CRM, Groupware, ECommerce and ERP systems. As stated by Johansson and Sudzina (2009), "Open Source ERPs seem to be of an increasing interest at the moment. It could be asked if this interest is a result of dissatisfaction with proprietary ERPs or if it is a result of maturity in the open source phenomenon", FLOSS ERP solutions raise, and their target groups include mostly SMEs. The Ministry of Agriculture and Maritime Fisheries in Morocco published a report titled "The Moroccan Agriculture in numbers 2012" in which it stated that "At the national level, agriculture remains the main source of employment, followed far behind by other economic sectors. In rural areas, almost three-quarters of the working 
population gets its income of the agricultural industry.", this gives more weight to the reason for choosing a Moroccan Agribusiness SME as our case study.

Boldyreff (2005) stated that "ERP crosses over two different disciplines: software engineering and business expertise. In other words, dealing with EISs like ERP requires business expertise as well as technical expertise. This may have hindered the progress of the research in this area."

Thus, the purpose of this paper is to raise the elements that may support or daunt the adoption of FLOSS ERP systems, through the support of a Moroccan SME operating in the field of agricultural business, during its ERP adoption and implementation processes. Do FLOSS ERP systems present an opportunity for Moroccan SMEs? To answer this question we start by defining SMEs from the Moroccan legislator and professional group of banks point of view, then we give definitions for both ERP and FLOSS from the literature. Finally, we present the results of our case study, discuss them and enumerate the different study limitations. Observations and practical feedback relevant to this case study cannot be but of certain added value to the scientific and non-academic Information System communities.

\section{Moroccan Small and Medium Sized Enterprise Characteristics}

The Small and medium sized Enterprise Charter in Morocco (Law No. 53 - 00, July 2002) states that SMEs are: "any business managed and/or administered directly by individuals who are shareholders, and is not owned by more than $25 \%$ of capital or the voting rights by one enterprise or several enterprises, falling outside the SME definition". This threshold may be exceeded if the business is owned by: collective investment funds; corporate capital investment; venture capital organizations; and financial institutions duly authorized to use public savings to make financial investments, which do not exercise, individually or jointly, any control over the company.

In addition, Article 1 of Law No. 53 - 00 of 23 July 2002 relating to the forming Charter for SMEs provides the defining criteria of SMEs in Morocco differentiating between existing businesses and newly created companies (less than two years of existence).

Table 1: Conditions to be met by Moroccan SMEs according to the Moroccan Charter for SMEs

\begin{tabular}{|c|c|c|}
\hline \multicolumn{2}{|c|}{ Existing businesses (Existence $>2$ years) } & $\begin{array}{c}\text { Newly created } \\
\text { companies(Existence }<2 \\
\text { years) }\end{array}$ \\
\hline \multicolumn{2}{|c|}{ Permanent number of workers not exceeding 200 people } & NONE \\
\hline \multirow[t]{2}{*}{$\begin{array}{l}\text { Must have reached, } \\
\text { over the last two } \\
\text { years: }\end{array}$} & $\begin{array}{l}\text { Either an annual revenue below } 75 \\
\text { million dirhams after taxes. }\end{array}$ & $\begin{array}{l}\text { Engage in initial global } \\
\text { investment not exceeding } 25 \\
\text { million dirhams }\end{array}$ \\
\hline & $\begin{array}{l}\text { Or a total annual balance sheet less than } \\
50 \text { million dirhams. }\end{array}$ & $\begin{array}{l}\text { Maintain a ratio of } \\
\text { investment per job less than } \\
250,000 \text { dirhams }\end{array}$ \\
\hline
\end{tabular}

Achargui Amine Arrahmane and Zaouia Abdellah (2016), Journal of African Research in Business \& Technology, DOI: 10.5171/2016. 636830 
As claimed by Makhroute et al. 2013, this definition is never final and may be changed, according to the economic and social circumstances, to accommodate economic operators and institutions. A Joint Committee, composed of representatives of Bank Al-Maghrib and the Professional Group of Banks in Morocco "GPBM", elaborated a new bank rating system that allows the alignment of Moroccan banks to new standards from European agreements "Bale II". The proposed new system provides rating scales differentiating companies according to their size (large enterprises, SMEs, microenterprises).

Table 2: SME Criteria Defined by Bank Al-Maghrib and the Professional Group of Banks in Morocco "GPBM"

\begin{tabular}{|l|l|l|l|}
\hline Company size & Permanent workforce & Revenues & Total balance sheet \\
\hline Large enterprise & $>250$ Employees & $>75$ millions dirhams & $>90$ millions dirhams \\
\hline SME & $<250$ Employees & $<75$ millions dirhams & $<90$ millions dirhams \\
\hline Micro-enterprise & $<10$ Employees & $<10$ millions dirhams & $<15$ millions dirhams \\
\hline
\end{tabular}

Considering the richness of Morocco's soil, the agricultural sector is dominant. Agriculture is the mainstay of the Moroccan economy, since it accounts for $15 \%$ of Morocco's GDP and employs about $40 \%$ of the working population of the country (Ministry of Agriculture and Maritime Fisheries, 2012): as in most emerging countries, it retains a central role in society, but it is also a strategic sector for yielding currencies.

\section{Enterprise Resource Planning System}

ERP systems are enterprise-wide software packages that provide fully integrated business processes using a common database and offering data visibility and information from various viewpoints (Stefanou 2012). An ERP system is defined as standardized packaged software designed to integrate an organization's entire value chain (LengnickHall et al., 2004; Rolland and Prakash, 2000) and according to Alshawi (2004), "An enterprise resource planning (ERP) system is an attempt to create an integrated product that manages the majority of operations in a company. What is different about ERP systems is that they integrate across functions to create a single, unified system rather than a group of separate, insular applications". It is an integrated modular application software package that is designed to serve and support multiple business functions and which treats those business functions as a cohesive whole, allowing data to be shared between different functions, departments and units. Wier et al. (2007) argue that the aim of ERP systems is to incorporate business processes as well as ICT into a coordinated set of procedures, applications and metrics that can work over the boundaries of firms. ERP systems are all inclusive applications that can perform specific critical organizational functions. It makes the information flow smooth and dynamic. The purpose is to make the information flow instant and eliminate data redundancy, and to add more flexibility. It allows different units of the organization to come under one infrastructure. The data integration allowed by the ERP empowers the re-use of the data across all the systems (Mushtaq Ali Shah, S and Huq, N., 2010).These ERP systems are built to manage all the enterprise activities through independent software modules. All these activities are connected and interact simultaneously and therefore, the database is continually updated (Baratashvili, $\mathrm{T}$ and Machtidze, T., 2014). 
Each ERP software module is focused on one area of business processes and addresses one specific function among many, like accounting, human resources, sales, warehouse and purchases. This functional organization adds to the flexibility of the ERP product as each module can be individually purchased or developed, based on what best meets the specific needs and technical capabilities of the organization. In occurrence, ERP software systems are usually packaged in functional -piecesmodules that can be implemented in various combinations. This modular design also allows software developers to put together product offerings for specific industries and focus on specific functional needs while not re-inventing the wheel by duplicating the more universal functions like inventory control and purchasing.

\section{Free / Libre Open Source Software}

When we call software "free" we mean that it respects the users' essential freedoms: the freedom to run it, to study and change it, and to redistribute copies with or without changes. A program is free software if it gives users adequately all of these freedoms. Otherwise, it is nonfree. This is a matter of freedom, not price, so think of "free speech", not "free beer", as stated by Richard Stallman one of the most forceful and famous practitioners/theorists of free software.

There are three entities in the Free Software movement where people turn to for evaluations of Free Software licenses: The Free Software Foundation (FSF), the Debian project and the Open Source Initiative (OSI). Historically, "Free Software" was the first term created, and a first documented complete definition that presents the criteria for whether a particular software program qualifies as free software, appears to be the GNU's Bulletin, vol.1 no.1, published on February 1986. Thus according to the FSF, a program is free software if the program's users have the four essential freedoms listed in the table below:

Table 3: The Free Software Definition of the Free Software Foundation

\begin{tabular}{|l|l|}
\hline (freedom 0) & The freedom to run the program as you wish, for any purpose (freedom 0). \\
\hline (freedom 1) & $\begin{array}{l}\text { The freedom to study how the program works and change it so it does your } \\
\text { computing as you wish (freedom 1). Access to the source code is a precondition } \\
\text { for this. }\end{array}$ \\
\hline (freedom 2) & The freedom to redistribute copies so you can help your neighbor (freedom 2). \\
\hline (freedom 3) & $\begin{array}{l}\text { The freedom to distribute copies of your modified versions to others (freedom } \\
\text { 3). By doing this you can give the whole community a chance to benefit from your } \\
\text { changes. Access to the source code is a precondition for this. }\end{array}$ \\
\hline
\end{tabular}

On July 5, 1997, The producers of the Debian system, a project aiming to create a completely free and community based GNU/Linux distribution, have created the "Debian Social Contract" where they designed and defined the "Debian Free Software Guidelines" (DFSG) as a set of commitments that the Debian producers agree to abide by, as well as a check-list to decide whether a program can be included in the Linux distribution or not, as advanced by B. Schießle (May 11th, 2012).
In 1998 the Open Source Initiative was set up as a marketing campaign for Free Software and introduced the Open Source definition and the goal was to seek fast commercialization of Free Software and acceptance of Free Software by the companies and venture capitalists of the booming new economy. The OSI, by copying the DFSG, replacing "Free Software" with "Open Source" and removing the Debianspecific references from the DFSG, has created The Open Source Definition. 
When the European Commission started dealing with Free Software on a regular basis, they sought to avoid the ambiguity of the English word "Free Software" and the misunderstandings of "Open Source" alike, which led to the adoption of a third term which has popped up occasionally since around 1992: "Libre Software." This term has proven resistant to inflationary usage and is still used in an identical way to Free Software. So it may pose a solution for those who fear being misunderstood when speaking English; as advanced by the Free Software Foundation Europe.

Table 4: Criteria for defining Free Software according to the DFSG and open source software according to the Open Source Initiative

\begin{tabular}{|l|l|}
\hline The Debian Free Software Guidelines (DFSG) & The Open Source initiative (OSI) \\
\hline Free Redistribution & Free Redistribution \\
\hline Source Code & Source Code \\
\hline Derived Works & Derived Works \\
\hline Integrity of The Author's Source Code & Integrity of The Author's Source Code \\
\hline No Discrimination Against Persons or Groups & No Discrimination Against Persons or Groups \\
\hline No Discrimination Against Fields of Endeavor & $\begin{array}{l}\text { No Discrimination Against Fields of } \\
\text { Endeavor }\end{array}$ \\
\hline Distribution of License & Distribution of License \\
\hline License Must Not Be Specific to Debian & License Must Not Be Specific to a Product \\
\hline License Must Not Contaminate Other Software & License Must Not Restrict Other Software \\
\hline Example Licenses & License Must Be Technology-Neutral \\
\hline
\end{tabular}

At the end, Free Software, Libre Software and Open Source Software, all connote freedom, thus to settle the ambiguity around these used terms, Richard Stallman reported that a researcher studying practices and methods used by developers in the free software community decided that these questions were independent of the developers' political views, so he used the term "FLOSS," meaning "Free/Libre and Open Source Software," to explicitly avoid a preference between the two political camps. If you wish to be neutral, this is a good way to do it, since this makes the names of the two camps equally prominent.

\section{Methodology}

For an ERP project, like any other EIS projects, there are both the adoption and the appropriation phases. We present in this paper, the method used to tackle the selection step of the ERP project lifecycle for the case of Moroccan SMEs (figure 1). The method starts with listing all interesting FLOSS ERP systems, available, used by professionals and well renowned worldwide, then the same process should be done once again for the software selection restricted to the French-speaking countries. Afterwards, there comes the step of IT providers and Integrators selection for the ERP implementation to be assured and done. 


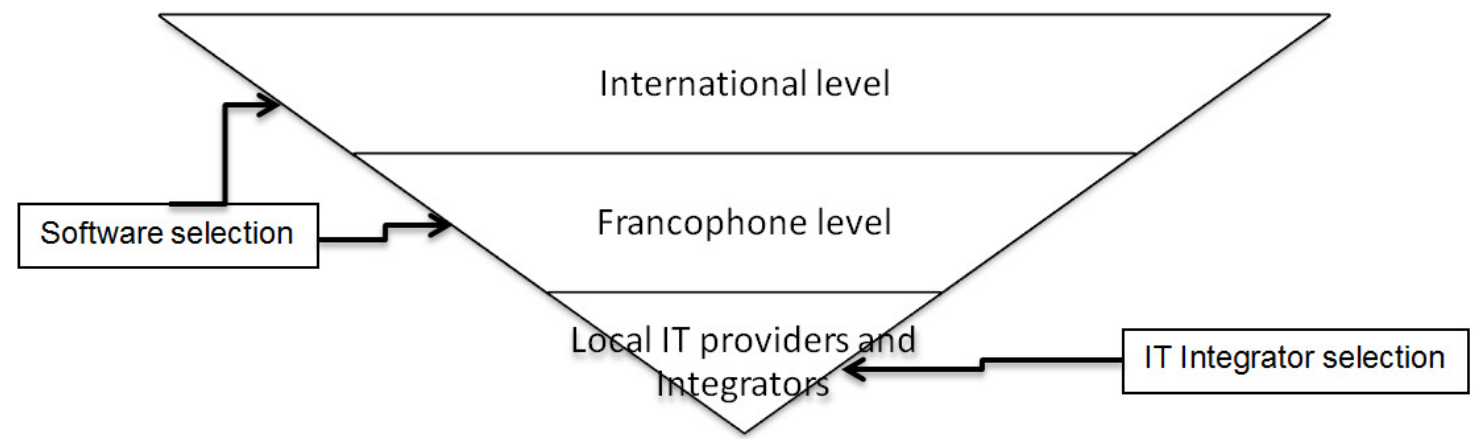

Figure 1: Proposed framework for the selection step of the ERP lifecycle, targeted to Moroccan SMEs

The annual InfoworldBossie Awards are given to the best and most innovative open source software products for end users, businesses and IT professionals in various categories, from InfoWorld that is an information technology media business founded in 1978. Their web site is considered to be the Web site for IT decision makers seeking to modernize their operations using the latest technologies, architectures, and strategies. First of these awards were announced in September 2007, and were given to 36 software applications across 6 categories: The best open source applications, The best open source application development tools, The best open source data center and cloud software, The best open source desktop and mobile software, The best open source networking and security software and The best open source big data tools. The software applications were adjudged by the InfoworldTest Center editors, contributors and reviewers. For the selection phase of an Open Source ERP, Odoo has been chosen for many reasons, based mainly on the best open source software applications "BOSSIE" winning awards for the three last years (table 5), then on the Open Source ERP systems recommended by Smile's white paper titled 'ERP, the best of FLOSS solutions' revision of 2015, accessed 20 March 2015 (figure 2), the Smile Enterprise is one of the leading open source players in France and Europe. Besides, it has received the award for Best European Partner of Odoo, the Enterprise is also very well renowned for its several white papers discussing different aspects of FLOSS systems and projects.

Table 5: Best of Open Source Applications According to inforworld.com 2012, 2013 and 2014 BOSSIE Awards

\begin{tabular}{|l|l|l|l|l|l|}
\hline $\begin{array}{l}\text { Years / FLOSS } \\
\text { Business Applications }\end{array}$ & ERPNext & xTuple & Odoo & OpenBravo & OpenTaps \\
\hline $\mathbf{2 0 1 4}$ & YES & YES & YES & YES & YES \\
\hline $\mathbf{2 0 1 3}$ & YES & YES & YES & YES & - \\
\hline $\mathbf{2 0 1 2}$ & - & YES & YES & YES & - \\
\hline
\end{tabular}




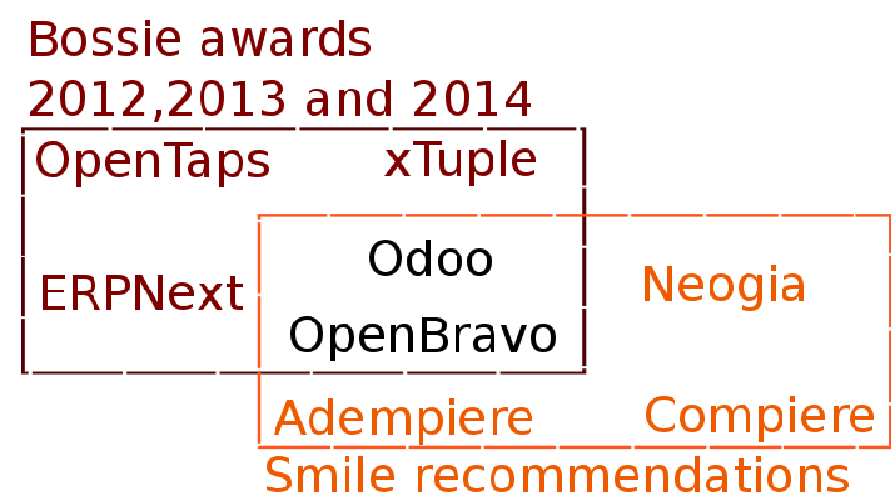

\section{Figure 2: An intersection of the investigation n's results on the best professional recommended FLOSS ERP systems}

We can clearly see that both Odoo and Open Bravo are the most recommended and agreed on FLOSS ERP systems to be used, and then comes the number of IT partners in Morocco that are able and well trained to support Moroccan SMEs ERP systems project implementation. A simple search on google, yahoo and bing search engines with "partenaireodoomaroc" as keywords for the search, gives us in the first results page, a minimum of 4 Odoo partners against only a maximum of 2 OpenBravo partners by using "partenaireOpenBravoMaroc", as listed in the table below:

Table 6: Comparison of the number of business partners in Morocco for both Odoo and OpenBravo in the first result page on all of Google, Yahoo and Bing search engines (Accessed on 20 March 2015)

\section{Results \& Discussion}

Serrano and Sarriegi (2006) state that the benefits of applying FLOSS are greater for ERPs than for other kinds of applications, for three main reasons:

(1) Increased adaptability. ERPs are not plug-and-play. They always need an implementation project to match the business processes and local regulations.
Having full access to the ERP source code can facilitate this unavoidable customization. Trade barriers, custom and technical regulations, tariff rates and import taxes, warranty and nonwarranty repairs, export controls, labeling/marking standards, conformity assessment, product certification, and accreditation overview, in addition to membership in Free Trade Agreements with the Maghreb Arab Union, Saudi Arabia, Jordan, Tunisia, Egypt, USA and EU, are all elements of an equation that proves the fact that Moroccan Agribusiness SMEs are highly flexible and adaptable to change, and so must be their EIS.

(2) Decreased reliance on a single supplier. Businesses that acquire a proprietary ERP are highly dependent on the product builders and distributors - that is, the source code's owners. If one, or even both, of these agents disappears, upgrading and maintaining the ERP can pose significant problems. An ERP system is a complex piece of software; therefore joining a promising and stable project is better than starting a 
new project from scratch in the bazaar style. This advice is aligned with the traditional wisdom of reuse as well. (Boldyreff, 2005) Especially with FLOSS ERP, where its FLOSS nature and modular design also allows any qualified software developer to put together product offerings for specific industries and customize the software to be adaptable to the ever changing functional needs while not re-inventing the wheel by duplicating the more universal functions like inventory control and purchasing. Customers benefit by not having to buy and maintain functionality that they don't want or need. Specialized Institutes of Applied Technology (ISTA) that is present in most of Moroccan cities, Students bearers of general university studies diploma, and State/Private schools of engineering graduates, are all potential system integrators or at least qualified software developers for the Moroccan local market, that can help decrease the reliance on a single supplier.

(3) Reduced costs. Proprietary ERP licenses are expensive. A rule of thumb puts them at between one-sixth and one-third of the implementation project costs. OSS ERPs avoid this cost. Furthermore, they usually do not need expensive hardware to run. Although Open Source systems do not have licenses costs, the probable budget is spent with IT staff and/or consultants (Gripe, F.G.S and Rodello, I.A., 2012). Besides, Boldyreff (2005) states that the ever-falling price of hardware has also contributed to the popularity of OSS. Unlike in the past, nowadays the cost of software applications could easily surpass that of the hardware components in a system. This reversal has forced suppliers and customers to rethink the conventional software licensing models used in business The SME, unit of study, expresses that the use of a web based ERP system is more important than it being FLOSS or proprietary, because of the costs of ERP software clients to be reinstalled each time viruses, and other sorts of malwares slow down the PCs on which the software clients are installed. In Morocco, reformatting and reinstalling a PC with an Operating System and Software utilities costs no more than 200 Moroccan dirhams, but re-installing the ERP software client can vary from 500 $\mathrm{dh}$ to $2000 \mathrm{dh}$, which will make the ERP system's total cost of ownership not affordable for SMEs, especially, when there are tens of system's users.

Once the ERP system selected, implemented and being used by the SME, the following was observed:

The ERP system appropriation rate can tumble down, once it comes to bills, taxes and margins, if the system does not give the SME the needed Adaptability and Flexibility.

\section{Study Limitations}

The period of time " 5 months" is enough for every aspect to be raised, except for aspects related to the evolvement and evolution of the SME's activity. So we can study the potential of the ERP system modularity.

Besides the very well renowned web-based source code repository "SourceForge", new source code repositories that host FLOSS projects in general have emerged, like Github and Bitbucket, and have gained in popularity among FLOSS developers and contributors, we will try to establish a clear and concise comparison of the different FLOSS ERP systems no matter where they are hosted. 
The SME, unit of our exploratory study, neither benefited from the "Imtiaz" nor the "Moussanada" programs launched by Morocco's National Agency for the Promotion of SMEs. It would be helpful to compare between the cases where an SME is eligible and takes advantage of one or both programs, with the actual case that does not benefit from any of them both.

\section{Conclusion}

Ultimately, Boldyreff (2005) mentioned that looking at the number of reported research on Open Source ERP published in Scientific and Academic journals and proceedings, compared to the numerous articles that have been published in non-academic industrial trade magazines, implies that currently there is a gap between the market demand and the research carried out by academics.

In this paper, we have found that FLOSS ERP systems adoption is not of an issue for Moroccan SMEs, unless it is not a web based ERP system, for it being used on-line through Internet, as a Cloud solution or only accessible from a local area network; we have proposed a selection framework depending essentially on two factors, the software factor and the business partner factor. Furthermore, a FLOSS ERP system, despite taking advantage of the four freedoms of a FLOSS license, sees its appropriation rate tumbles down, depending on the flexibility and adaptability that the system offers concerning bills, taxes and margins.

In terms of managerial implications, the findings presented are of interest for both SMEs that want to adopt a FLOSS ERP system and look for a successful ERP implementation and for IT providers and integrators that target Moroccan SMEs' Information Systems; it is shown that there are cultural and organizational reasons other than the costs involved when deciding on which ERP system to choose.

\section{References}

1. Alshawi, S., Themistocleous, M.andAlmadani, R., (2004), 'Integrating Diverse ERP Systems: a Case Study', The Journal of Enterprise Information Management, Vol. 17, No. 6, 2004, pp.454462.

2. Aversano, L., Pennino, I. and Tortorella, M., (2011), 'Evaluating the quality of free/open source ERP systems', 12th International Conference, ICEIS 2010, Funchal-Madeira, Portugal, June 8-12, 2011, vol.73, pp.119-134

3. Baratashvili, T and Machtidze, T. (2014), 'Open source ERP - new opportunities for Georgian small and medium enterprises', Ilia State University, Tbilisi

4. Boldyreff, C and Kim, H., (2005) 'Open source ERP for SMEs'. ICMR 2005, 6-8 Sept 2005, Cranfield University, U.K..

5. Johansson, B and Sudzina, F, (2009) 'Choosing open source ERP systems: what reasons are there for doing so?', Open Source Ecosystems : Diverse Communities Interacting, 143-155.

6. Debian Social Contract [online]. Available from:

https://www.debian.org/social_contract\#gui delines . [Accessed 20 March 2015].

7. FLOSS and FOSS [online]. Available from: http://www.gnu.org/philosophy/floss-andfoss.html. [Accessed 20 March 2015].

8. Fougatsaro, V. G. (2009), 'A study of open source ERP systems', School of Management, Blekinge Institute of technology, Blekinge.

9. Free Software, Open Source, FOSS, FLOSS - Same same but different [online]. Available from:http://blog.schiessle.org/tag/communi ty/.[Accessed 20 March 2015].

10. Gorishti, A. and Sevrani K. (2012), 'A survey on open source ERP and the reasons 
for their use by SMEs', International Journal of Science, Innovation \& New Technology, July 2012, p1.

11. Gripe, F.G.S and Rodello, I.A. (2012), 'A brief survey of open source ERP systems usage on Brazilian organizations', Proceedings of IADIS International Conference Information Systems 2012, Berlin.

12. Interview: Richard M. Stallman [online]. Available from: http://www.gnu.org/philosophy/luisporms-interview.html . [Accessed 20 March 2015].

13. Johansson, B and de Carvalho, R.A. (2010), 'Enterprise resource planning systems for small and medium - sized enterprises', Handbook of Research on Software Engineering and Productivity Technologies: Implications of Globalisation p.373-381 Engineering Science Reference

14. Johansson, B and Sudzina, F., (2008), 'ERP systems and open source : an initial review and some implications for SMEs', Journal of Enterprise Information Management, vol. 21 no. 6, 2008, pp.649-658.

15. Lengnick-Hall, C.A., Lengnick-Hall, M.L. and Abdinnour-Helm, S. (2004), "The role of social and intellectual capital in achieving competitive advantage through enterprise resource planning (ERP) systems", Journal of Engineering \& Technology Management, Vol. 21 No. 4, pp. 307-30.

16. Lord Kelvin, (May 3rd, 1883), 'Lecture on "Electrical Units of Measurement".' Popular Lectures, Vol. 1, page 73.

17. Makhroute, M., Morsli, A., Tawafi I. and Rholam Y., (2013), 'The Issue of the Definition of Moroccan SMEs and Different Approaches', Journal of US-China Public Administration, ISSN 1548-6591 May 2013, Vol. 10, No. 5, pp. 488-496.
18. Ministry of Agriculture and Maritime Fisheries (2012) 'The Moroccan Agriculture in numbers 2012', Kingdom of Morocco.

19. Ministry of Finance and Privatization (August 2003), 'Evaluation of SME financing in Morocco', Kingdom of Morocco.

20. Morocco. (2002). Charter for Small and medium sized Enterprise, Law No. 53-00, Article No. 1.

21. Mushtaq Ali Shah, S and Huq, N. (2010), 'Why selecting an open source ERP over proprietary erp? a focus on SMEs and suppliers perspective', Jonkoping university.

22. Olson, D.L., Staley, J. (2010), 'Case study of open source ERP evaluation in a small business', University of Nebraska, Lincoln, NE 68588-0491.

23. Rolland, C. and Prakash, N. (2000), "Bridging the gap between organisational needs and ERP

24. functionality", Requirements Engineering, Vol. 5 No. 3, pp. 180-93.

25. Serrano, N.S. and Sarriegi, J.M. (2006), 'Open source software ERPs : a new alternative for an old need', IEEE Software, Vol.23, No.3, pp.94-97.

26. Stefanou, C. J. (2012). SMEs and FOS-ERP systems: Risks and opportunities. In R. A. Carvalho\& B. Johansson (Eds.), Free and open source enterprise resource planningsystems and strategy (pp. 134-143). USA: Business Science Reference, IGI Global.

27. Stefanou , C. J. (2013), 'Adoption of Free/Open Source ERP Software by SMEs', Information Systems for Small and mediumsized Enterprises Progress in IS, 2014, pp.157-166.

28. The Open Source Definition [online]. Available from: http://opensource.org/osd. [Accessed 20 March 2015]. 
29. What is free software? [online]. Available from:

https://fsfe.org/about/basics/freesoftware. [Accessed 20 March 2015].

30. What is free software? [online]. Available from: https://gnu.org/philosophy/freesw.html. [Accessed 20 March 2015].

31. Why Open Source misses the point of Free Software [online]. Available from: http://www.gnu.org/philosophy/opensource-misses-the-point.html. [Accessed 20 March 2015].

32. Wier, B., Hunton, J., \&HassabElnaby, H.R. (2007).Enterprise resource planning systems and nonfinancial performance incentives.The joint impact on corporate performance.International Journal of Account.Inf. Systems 8, 165-190. 